\title{
Soil Inertia and Shallow Basement Envelope Impact on Cellar Internal Temperature
}

\author{
Naima Sakami ${ }^{1}$, Lahcen Boukhattem ${ }^{1}$, Hassan Hamdi² \\ ${ }^{1}$ EnR2E, CNEREE, Cady Ayyad University, Marrakech, Morocco \\ 2 LMFE URAC27-CNRST, FS, Cady Ayyad University, Marrakech, Morocco \\ sakami.na3@gmail.com
}

\begin{abstract}
This study deals with a three dimensional numerical study of heat transfer by conduction between the soil and the shallow basement in the city of Marrakech (Morocco). The heat transfer equation is solved by the finite difference method using the implicit alternative direction (ADI). The internal temperature of the cellar is computed by using energy balance equation in the cellar. The objective of the study is to evaluate the effects of the nature of the soil, the nature of the walls, the thickness of the walls of the cellar, the distance $L$ far from the cellar on the internal temperature, and the heat exchanged between the soil and the shallow basement.
\end{abstract}

Keywords - ADI Scheme; Internal temperature; Nature of soil; Basement; Heat flow.

\section{Nomenclature -}

$\mathrm{L}$ Distance delimiting the disrupted area along $\mathrm{x}$ axis, $m$

D Distance delimiting the disrupted area along $y$ axis, $m$

$H$ Depth of the water table, $m$

E Thickness, $m$

$\mathrm{T}$ temperature, ${ }^{\circ} \mathrm{C}$

$\mathrm{Cp}$ Specific heat, $\mathrm{J} \mathrm{kg}^{-1} \mathrm{~K}^{-1}$

$\rho$ Density, $\mathrm{kg} / \mathrm{m}^{3}$

$\lambda$ Thermal conductivity, $\mathrm{W} / \mathrm{mK}$

dS Internal elementary surface of the wall, $\mathrm{m}^{2}$

$\mathrm{t}$ Time, $\mathrm{s}$

$h_{c}$ The overall exchange coefficient, $W^{-2} K^{-1}$

$\checkmark$ Volume of shallow basement, $\mathrm{m}^{3}$

a Thermal diffusivity, $\mathrm{m}^{2} / \mathrm{s}$

$q$ Mass flow rate of fresh air, $\mathrm{kg} / \mathrm{s}$

\section{SUBSCRIPTS -}

$\begin{array}{ll}\mathrm{a} & \text { Air } \\ \mathrm{amb} & \text { Ambient } \\ \mathrm{m} & \text { Wall } \\ \mathrm{p} & \text { Floor }\end{array}$

$\begin{array}{ll}\text { s } & \text { Soil } \\ \text { w } & \text { Water table } \\ \text { wall } & \text { Wall surface } \\ \text { int } & \text { Inside shallow basement }\end{array}$

\section{INTRODUCTION}

The interest of the study of the heat transfer in the basement is to show the importance of the soil inertia in the hot regions such as Marrakech. Owing to the very high thermal capacity of the soil, the temperature of the ground is lower than that of the outdoor air in the summer and higher in the winter. Consequently, the heating and cooling energy of a building considerably sunk into ground is lower than that one above the ground.

Thus, accurate estimation of loads and energy consumption due to thermal interactions between a building and the ground is needed. This is a difficult task since this analysis needs to include the multidimensional nature of most earth-coupled heat transfer processes, large phase lags caused by soil thermal mass, limited practical ability to model soil thermal proprieties and the variability of soil temperature with ground surface conditions [1]. It is difficult to derive analytical solutions for 3D transient ground-coupled heat transfer even for the simple rectangular slab-on-ground problem. The only available 3D analytical expression is the steady-state solution derived by Delsante et al. [2] for a rectangular slab-on-ground with the assumption of a linear temperature distribution along the base (wall/ground interface) of the external walls. A semianalytical method inter-zones temperature profile estimation (ITPE) has been developed by Krarti et al. [3]. It combines analytical solutions for regularshaped components and numerical techniques to connect these components to construct the ground model. The ITPE method is used to calculate the approximate analytical solutions for the three- 
dimension heat transfer between slab-on-grade floors and rectangular basements under steady-periodic conditions. W.R. Bahnfleth developed a detailed three-dimensional finite difference model for heat conduction from slab-on-grade floors and basements, including a detailed ground surface energy balance. [4]. M. P. Deru [5] used the two dimensional finite element to study the effects of moisture on the heat transfer from two basic types of building foundations, a slab-on-grade and a basement. A two-dimensional finite element heat and moisture transfer program is used to show the effects of precipitation, soil type, foundation insulation, water table depth, and freezing on the heat transfer from the building foundation. Recently M. Staniec and H. Nowak [6] determined the earth sheltered building's heating and air-conditioning energy demand depending on the type of soil in which it is founded. For comparison, the corresponding results for the above ground building are presented.

In Marrakech, several studies have been made to analyze the heat exchange between the ground and a building. A. Abdelbaki generated a two-dimensional transfer function coefficients (TFC) for a slab-ongrade floor [7]. Later, TFC have been derived successfully for shallow basement $[8,9]$ and earthsheltered building [10]. It has been shown [7, 9] that the results obtained using the transfer functions method fully agree with those obtained using the ITPE technique and the ADI technique. Recently L. Boukhattem [11, 12] used the ADI method to study the effects of the parameters of mortar on the heat exchange between the soil and the two buildings: buried building and semi-buried building.

In this work, the researchers have developed a computer code that allows them to study the effect of the nature of the soil, the nature of the walls of the underground building, the thickness of the walls, the distance $L$ of the disrupted area on the internal temperature, and the heat exchanged between the soil and the shallow basement.

\section{MATHEMATICAL FORMULATIONS AND BOUNDARY CONDITIONS}

\section{A. Configuration of the studied Shallow basement}

The configuration treated in this work is illustrated in Figure 1. The basement has a rectangular shape with $a$ width of $2 b$, a length of $2 a$ and a depth of $c$. The wall and the floor are assumed to have identical thermal conductivity and thermal diffusivity.

The results presented in this section are obtained for: $\mathrm{a}=2 \mathrm{~m} ; \mathrm{b}=2 \mathrm{~m} ; \mathrm{c}=2 \mathrm{~m}$ and $e_{m}=0.26 \mathrm{~m}$

The overall heat transfer coefficient $[3,8,11]$ is: $\mathrm{h}_{\mathrm{c}}=8.30 \mathrm{Wm}^{-2} \mathrm{~K}^{-1}$.

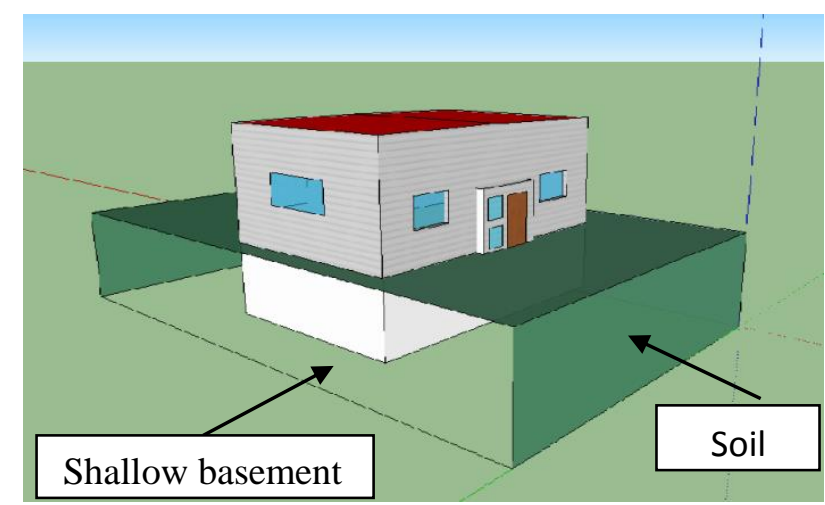

Fig .1. Building with a shallow basement

Because of the symmetry of the studied configuration, the study is reduced to a quarter of the shallow basement (Figure 2)

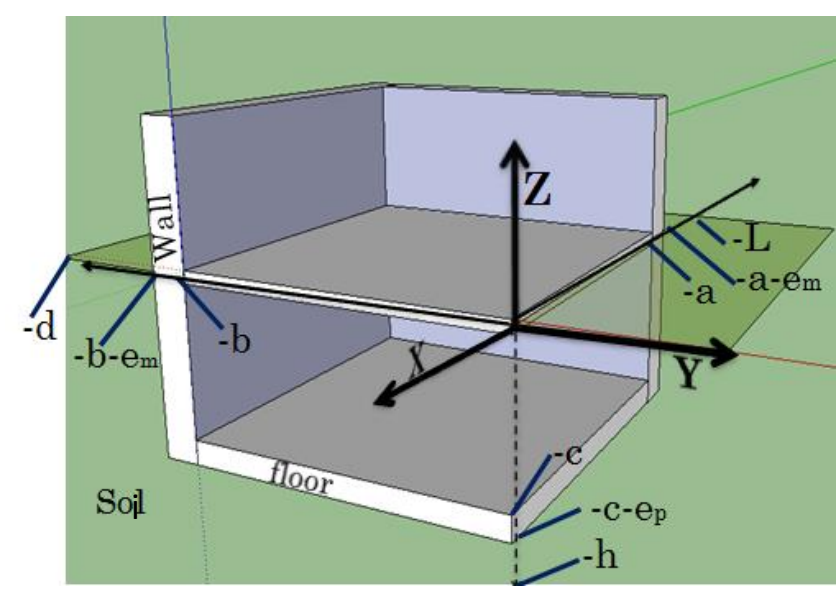

Fig .2. Shallow basement configuration

\section{B. Mathematical model}

The unsteady three-dimensional heat transfer equation can be written as follows:

$\rho C_{P} \frac{\partial T}{\partial t}=\lambda\left(\frac{\partial^{2} T}{\partial x^{2}}+\frac{\partial^{2} T}{\partial y^{2}}+\frac{\partial^{2} T}{\partial z^{2}}\right)$

This equation was solved by an improved alternatingdirection-implicit (ADI) finite-difference numerical method. A FORTRAN program was built for this analysis. 
Minimum cell dimensions were established in accordance with the accuracy and stability criteria set forth by the numerical method employed in the study. Grid spacing in the present model in the vicinity of the building foundation ranged from $0.2 \mathrm{~m}$ to $0.3 \mathrm{~m}$, while spacing at far-field and deep-ground boundaries was as large as $1.3 \mathrm{~m}$.

\section{Real climate of Marrakech}

The simulation by the ADI method is made by considering the real ambient temperature of Marrakech. This temperature was measured by the weather station of AGDAL Marrakech. Figure 3 shows the variation of medium ambient temperature during one year (2008).

The water table at a depth of $13 \mathrm{~m}$ below the soil surface is maintained constant at $20^{\circ} \mathrm{C}$.

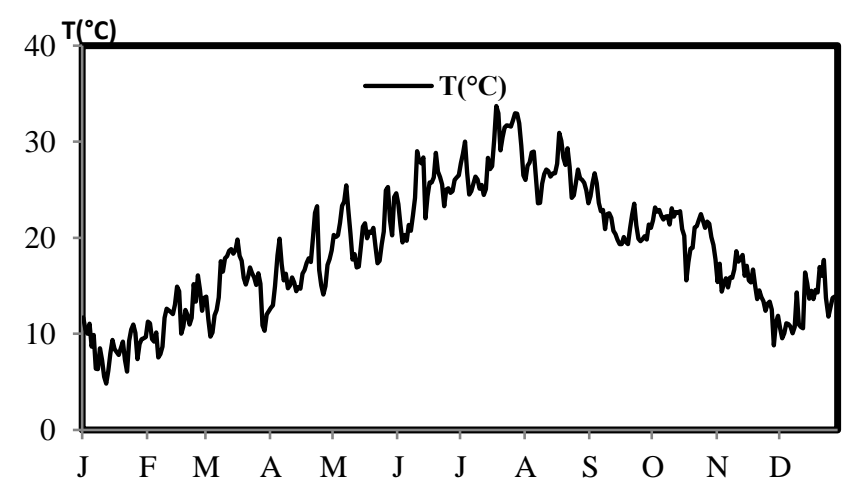

Fig .3. External air temperature

The Boundary conditions of the studied problem are:

- In the two planes of symmetry:

$$
\left.\frac{\partial T_{\mathrm{int}}}{\partial x}(x, y, z, t)\right|_{x=0}=0
$$

For $-d \leq y \leq 0$ and $-h \leq z \leq 0$

$$
\left.\frac{\partial T_{\mathrm{int}}}{\partial x}(x, y, z, t)\right|_{y=0}=0
$$

For $-L \leq x \leq 0$ and $-h \leq z \leq 0$

- Far from building:

$$
\left.\frac{\partial T_{s}}{\partial x}(x, y, z, t)\right|_{x=-L}=0
$$

For $-d \leq y \leq 0$ and $-h \leq z \leq 0$

$$
\left.\frac{\partial T_{s}}{\partial y}(x, y, z, t)\right|_{y=-d}=0
$$

For $-L \leq x \leq 0$ and $-h \leq z \leq 0$

- Interfaces internal air-side of the building :

$$
-\left.\lambda_{s} \frac{\partial T_{s}}{\partial x}(x, y, z, t)\right|_{x=-a}=h_{c}\left(T_{s}(-a, y, z, t)-T_{\text {int }}\right)
$$

For $-b \leq y \leq 0$ and $-c \leq z \leq 0$

$$
-\left.\lambda_{s} \frac{\partial T_{s}}{\partial y}(x, y, z, t)\right|_{y=-b}=h_{c}\left(T_{s}(\mathrm{x},-b, z, t)-T_{\mathrm{int}}\right)
$$

For $-a \leq x \leq 0$ and $-c \leq z \leq 0$

$-\left.\lambda_{s} \frac{\partial T_{s}}{\partial z}(x, y, z, t)\right|_{z=-c}=h_{c}\left(T_{s}(\mathrm{x}, y,-c, t)-T_{\mathrm{int}}\right)$

For $-a \leq x \leq 0$ and $-b \leq y \leq 0$

- Interfaces soil-external walls of building :

$\left.\lambda_{m} \frac{\partial T_{m}}{\partial x}(x, y, \mathrm{z}, t)\right|_{x=-(a+e \mathrm{~m})}=-\left.\lambda_{s} \frac{\partial T_{s}}{\partial x}(x, y, \mathrm{z}, t)\right|_{x=-(a+e \mathrm{~m})}$

For $-b-e_{m} \leq y \leq 0$ and $-c-e_{m} \leq z \leq 0$

$\left.\lambda_{m} \frac{\partial T_{m}}{\partial x}(x, y, \mathrm{z}, t)\right|_{y=-(\mathrm{b}+e \mathrm{~m})}=-\left.\lambda_{s} \frac{\partial T_{s}}{\partial x}(x, y, \mathrm{z}, t)\right|_{y=-(\mathrm{b}+e \mathrm{~m})}$

For $-a-e_{m} \leq x \leq 0$ and $-c-e_{m} \leq z \leq 0$

$\left.\lambda_{m} \frac{\partial T_{m}}{\partial x}(x, y, \mathrm{z}, t)\right|_{z=-(\mathrm{c}+\mathrm{em})}=-\left.\lambda_{s} \frac{\partial T_{s}}{\partial x}(x, y, \mathrm{z}, t)\right|_{z=-(\mathrm{c}+\mathrm{em})}$

For $-a-e_{m} \leq x \leq 0$ and $-b-e_{m} \leq y \leq 0$

- Air temperature and water table temperature:

$T(x, y, 0)=T_{a m b}$ and $T(x, y,-\mathrm{h})=T_{w}$

For $-L \leq x \leq 0$ and $-d \leq y \leq 0$

The heat flow is calculated by the following equation: 


$$
\text { Heat flow }=\sum h_{c} d S\left(T_{\text {int }}-T_{\text {wall }}\right)
$$

\section{The local heat balance}

The energy conservation law for the internal medium of the shallow basement, which is considered as an open system is:

$$
\frac{d E}{d t}=\frac{\delta Q}{\delta t}+\frac{\delta W}{\delta t}
$$

$E$ is the total internal energy of the medium;

$Q$ is the heat crossing the system boundary;

$W$ is the total work that is a sum of the work done by the pressure forces on the control surface and the flow work.

Thus, the volume $\mathrm{V}$ of the control volume remain constant, and as a result, the boundary work is zero.

The kinetic and potential energies of air in the cellar are neglected.

The air is considered as an ideal gas and the temperature of this one is uniform in the studied cellar, From the above assumptions, the equation 14 reduces to:

$$
\rho_{a} C_{p_{a}} V \frac{\partial T_{\mathrm{int}}}{\partial t}=q C_{p_{a}}\left(T_{a m b}-T_{\mathrm{int}}\right)+\sum_{i=1}^{3} h_{c} d s\left(T_{\mathrm{int}}-T_{\text {wall }}\right)
$$

\section{RESULTS AND INTERPRETATION}

\section{A. Code validation}

The researchers have elaborated a code that calculates the exchanged heat flow between a soil and shallow basement in 2D and 3D configurations. For computer code validation, they compared the results obtained by the present code and those of $\mathrm{M}$. Krarti [10] carried out for the same geometric which is characterized by depth $\mathrm{b}=3 \mathrm{~m}$, width $\mathrm{a}=2 \mathrm{~m}$, total width $\mathrm{L}=9 \mathrm{~m}$ and for thick walls $\mathrm{e}=0.4 \mathrm{~m}$ in $3 \mathrm{D}$ configuration.

A non-uniform mesh in both directions, constructed using a geometric progression, was adopted with $36 \times 38$ grid dimension. Figure 4 shows good agreement between the results obtained by the proposed code and those of S. Amjad.
The heat flow is calculated by the following equation:

$$
\text { Heat flow }=\sum h_{c} d S\left(T_{\mathrm{int}}-T_{\text {wall }}\right)
$$

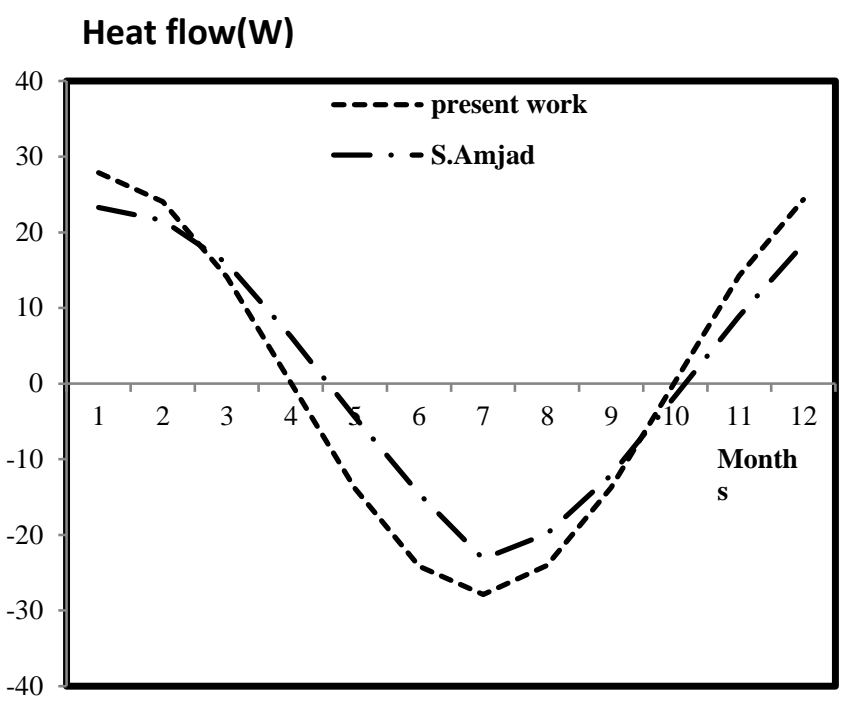

Fig .4. Variation of the monthly heat flux.

\section{B. Effect of the distance $L$}

At a large distance from the foundation, the effect of the shallow basement on the ground becomes negligible. To determine this distance, the researchers recognized several simulations by varying the distances $L$ each time. Table 1 shows the monthly heat flows for each distance. This result indicated that little or no change in predicted heat flow occurs when the far-field boundary is at $8 \mathrm{~m}$ or more away from the building.

Table 1. Heat flow for different distances $L$.

\begin{tabular}{|c|c|c|c|c|}
\hline Months & $\begin{array}{c}\text { heat flow } \\
L=2 \mathrm{~m}\end{array}$ & $\begin{array}{c}\text { heat flow } \\
L=4 \mathrm{~m}\end{array}$ & $\begin{array}{c}\text { heat flow } \\
L=6 \mathrm{~m}\end{array}$ & $\begin{array}{c}\text { heat flow } \\
L=8 \mathrm{~m}\end{array}$ \\
\hline J & 297.18 & 312.74 & 317.30 & 315.86 \\
\hline F & 214.30 & 225.51 & 228.80 & 227.76 \\
\hline M & 129.04 & 135.79 & 137.77 & 137.15 \\
\hline A & 100.70 & 105.97 & 107.51 & 107.03 \\
\hline M & -7.49 & -7.89 & -8.00 & -7.97 \\
\hline J & $-1.00 \mathrm{E}+02$ & $-1.06 \mathrm{E}+02$ & $-1.07 \mathrm{E}+02$ & $-1.07 \mathrm{E}+02$ \\
\hline JU & -205.34 & -216.10 & -219.24 & -218.24 \\
\hline A & -163.57 & -172.14 & -174.65 & -173.85 \\
\hline S & -31.26 & -32.90 & -33.38 & -33.22 \\
\hline O & -19.81 & -20.85 & -21.15 & -21.06 \\
\hline N & 118.40 & 124.60 & 126.41 & 125.84 \\
\hline D & 193.23 & 203.34 & 206.31 & 205.37 \\
\hline
\end{tabular}




\section{Effect of soil types}

To evaluate the soil type effect on the cellar internal temperature sensitivity to changes in the external environment, the researchers have performed simulations for three different soil types whose characteristics are presented in Table II.

Table 2. Characteristics of the studied soils.

\begin{tabular}{|c|c|c|c|}
\hline Types of soil & $\begin{array}{c}\text { Type } \\
1\end{array}$ & $\begin{array}{c}\text { Type } \\
2\end{array}$ & $\begin{array}{c}\text { Type } \\
3\end{array}$ \\
\hline Thermal conductivity $\mathrm{W} / \mathrm{mK}$ & 2.00 & 1.15 & 0.32 \\
\hline Thermal diffusivity $\left(10^{-7}\right) \mathrm{m}^{2} / \mathrm{s}$ & 1.100 & 0.613 & 0.267 \\
\hline
\end{tabular}

Figure 5 shows the change in the internal temperature of the cellar for three types of studied soil. The thermal conductivity and thermal diffusivity of wall and floor are $\lambda_{m}=1.73 \mathrm{~W} / \mathrm{mK}$, and $\alpha_{m}=9.3 .10^{-7} \mathrm{~m}^{2} / \mathrm{s}$, respectively.

In general, it is observed that there is stability in the internal temperature of the cellar throughout the year that can be explained by the considerable effect of inertia of the soil. This stability is even more important for soil 3 which is characterized by low conductivity and low thermal diffusivity.

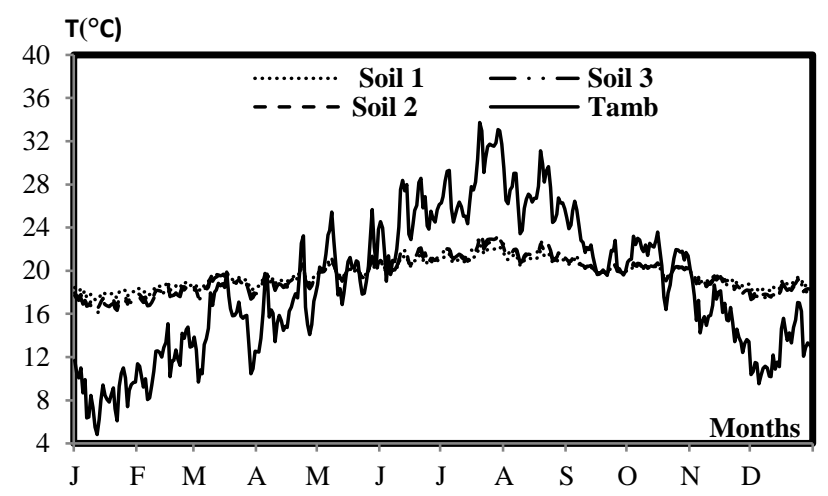

Fig .5. Daily variation of the external temperature and the internal temperature for three types of soil during a year.

In summer time, the outside temperature increases to $45^{\circ} \mathrm{C}$ while that of the interior does not exceed $25^{\circ} \mathrm{C}$ for sand and $23{ }^{\circ} \mathrm{C}$ for clay with $0.27 \%$ moisture content.

One can see a difference in indoor temperature between soil 2 and soil 3 . This is due to the moisture content that influences the internal temperature of the shallow basement (Figure 6).

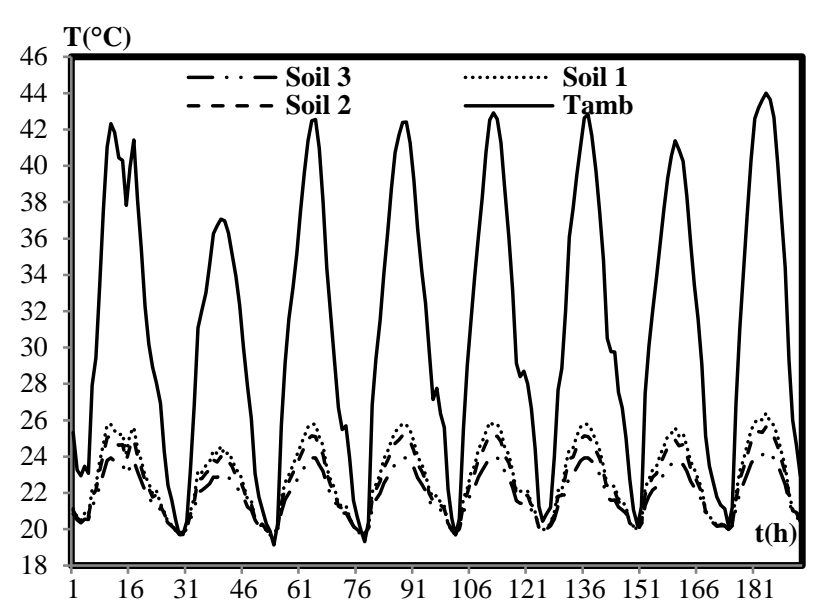

Fig .6. Hourly variation of indoor and outdoor temperature for one week of the summer period for three soil types.

During the winter period, the researchers found out that the cellar temperature does not descent below 16 ${ }^{\circ} \mathrm{C}$ for the three soil types, while the outer temperature recorded negative values in the range of $-1^{\circ} \mathrm{C}$. They also found out that the internal temperature provides stability throughout the day with a small amplitude of 2 ${ }^{\circ} \mathrm{C}$ for soil type 1 (clay) and $3^{\circ} \mathrm{C}$ for soil type 3 (sand) for a weather temperature that have an amplitude of $12^{\circ} \mathrm{C}$ (Figure 7).

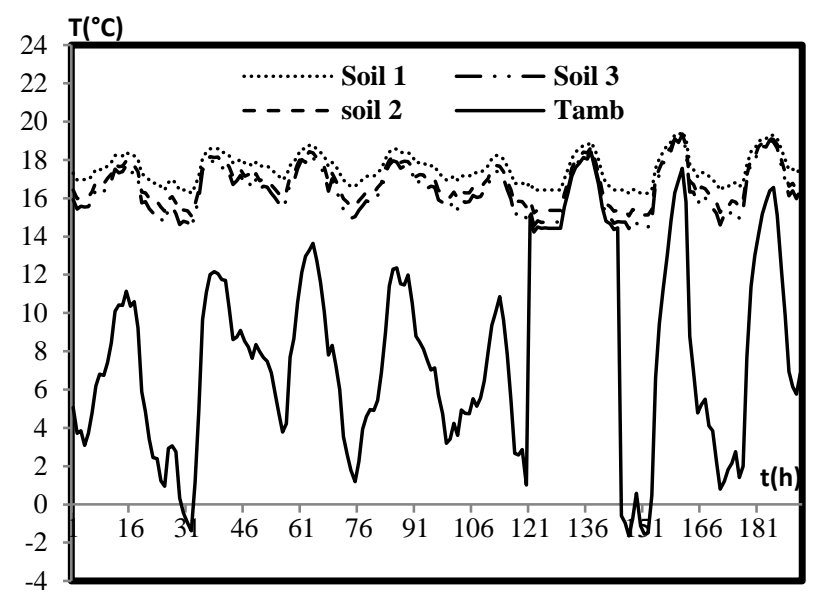

Fig .7. Hourly variation of indoor and outdoor temperature for one week of the winter period for three soil types.

Therefore, when analyzing the type of soil surrounding the building one should use accurate measurements of soil thermal proprieties (conductivity and diffusivity).

\section{Effect of the material type of the walls}

The determination of effect of construction materials on the internal temperature simulations was made for soil type 2 and for two building materials: reinforced 
concrete and hollow brick (Table III). The researchers observed that there is no significant difference between estimated temperatures for both materials. It can be deduced later that there is no effect on the nature of the walls of the internal temperature of the cellar for the studied cases (Figure 8).

Table 3. Characteristics of the studied walls.

\begin{tabular}{|c|c|c|}
\hline Material type of the walls & Hollow brick & $\begin{array}{c}\text { Reinforced } \\
\text { concrete }\end{array}$ \\
\hline Thermal conductivity $\mathrm{W} / \mathrm{mK}$ & 0.35 & 2.30 \\
\hline $\begin{array}{c}\text { Thermal diffusivity }\left(10^{-7}\right) \\
\mathrm{m}^{2} / \mathrm{s}\end{array}$ & 3.90 & 9.58 \\
\hline
\end{tabular}

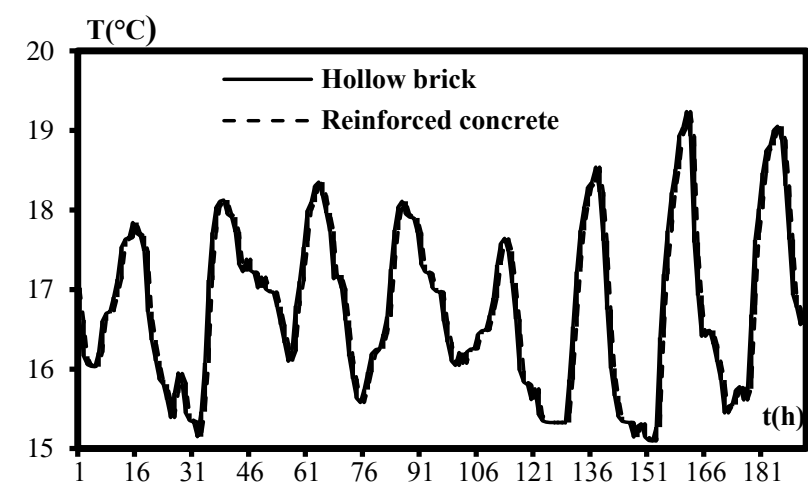

Fig .8. Hourly variation of indoor and outdoor temperature for one week of the summer period for two wall types.

\section{E. Effect of the thickness of the walls}

Figure 9 and Figure 10 are obtained for a soil type 2, reinforced concrete wall and for different wall thicknesses in the real climate of Marrakech. These results show that the influence of the wall thickness is not important; this is mainly due to the predominance of the thermal inertia of the soil compared to the walls cavity.

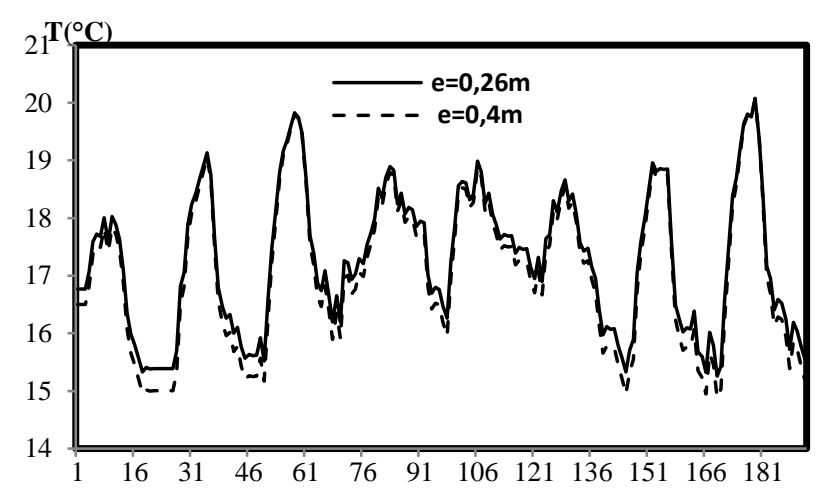

Fig .9. Hourly variation of the internal temperature for two thicknesses of the wall for a week during the winter period.

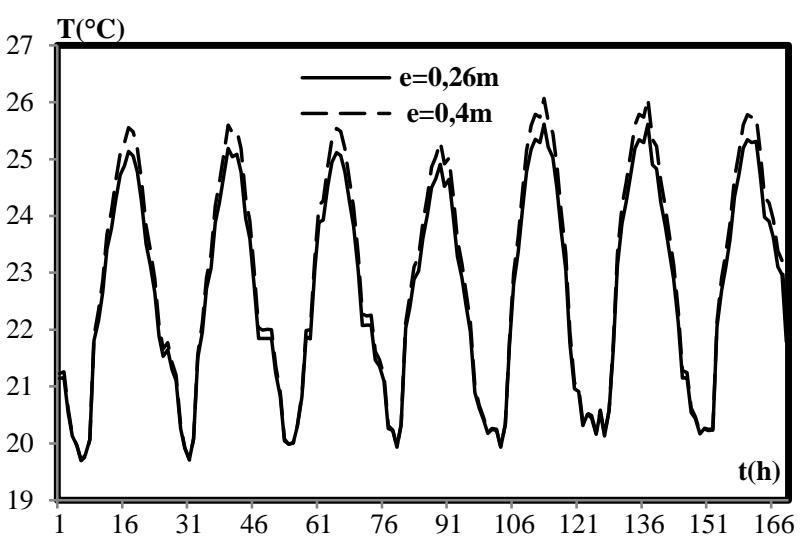

Fig .10. Hourly variation of the internal temperature for two thicknesses of wall for a week during the summer period

\section{CONCLUSION}

In this study, the researchers have developed a detailed FORTRAN code to calculate three dimensional heat transfers for an envelope in contact with the ground. It allowed them to calculate the exchange of heat between the soil and the basement through the use of finite difference method in three dimensions and also calculate the internal temperature of the cellar, in the real climate of Marrakech.

We demonstrated the significant effect of the inertia of the soil on the stabilization of the internal temperature of the cellar. Indeed, the average temperature inside the shallow basement varies between $16^{\circ} \mathrm{C}$ and $24^{\circ} \mathrm{C}$ throughout the year, with a magnitude of $8^{\circ} \mathrm{C}$. On the other hand, the ambient temperature is between $4^{\circ} \mathrm{C}$ and $34^{\circ} \mathrm{C}$ with the amplitude of $30^{\circ} \mathrm{C}$.

This inertia is largely influenced by the thermal characteristics of the soil. In fact; the internal temperature is more stable with the ground having a low thermal conductivity and thermal diffusivity. During the summer season, the internal temperature does not exceed $24^{\circ} \mathrm{C}$ (Soil 1) and $25^{\circ} \mathrm{C}$ (soil 3) when the ambient temperature reaches $44^{\circ} \mathrm{C}$. During the winter season, the ambient temperature descend down to $-2^{\circ} \mathrm{C}$, while the internal temperature did not descend below $15^{\circ} \mathrm{C}$ (soil 1) and $16^{\circ} \mathrm{C}$ (soil 3).

The study of the effect of the thickness of the wall and the wall-type shows that there is a difference of less than $1^{\circ} \mathrm{C}$ between the different studied situations (thickness and type of wall). So we can conclude that 
the type of wall and its thickness has little influence on the internal temperature of the cellar.

In conclusion, we deduce that the semi-buried building reduces the cooling and the heating loads through the stabilization of the internal temperature. On the other hand, the thermal characteristics of the ground are a great influence on the temperature inside the building in comparison to the type and thickness of the walls.

\section{ACKNOWLEDGEMENTS}

This study is a part of the RafriBAT project financially supported by a grant from the Hassan II Royal Academy of Sciences and Techniques, Morocco.

\section{REFERENCES}

[1] D. Chen, "Dynamic three-dimensional heat transfer calculation for uninsulated slab-onground constructions", Energy and Buildings, No 60, pp. 420-428, 2013.

[2] A.E. Delsante, A.N. Stokes, and P.J. Walsh, "Application of Fourier transforms to periodic heat flow into the ground under a building", International Journal of Heat Mass Transfer, Vol. 26, No.1, pp.121-132, 1983.

[3] S. Choi, M. Krarti, "Thermally optimal insulation distribution for underground structures", Energy and buildings, No.32, pp. 251-265, 2000.

[4] W.P. Bahnfleth, "A three-dimensional numerical study of slab-on-grade heat transfer", ASHRAE Transactions, No. 96, pp. 61-72, 1990.

[5] M.P. Deru, "Ground-coupled heat and moisture transfer from buildings", National Renewable Energy Laboratory. NREL/CP-550-29694, February 2001.
[6] M. Staniec and H. Nowak, "Analysis of the energy performance of earth-sheltered houses with southern elevation exposed", Eleventh International IBPSA Conference Glasgow, Scotland July 27-30, 2009.

[7] A. Abdelbaki, "Contribution à la modélisation des transferts thermiques à travers le plancher d'un habitat sur terre-plein", DES thesis, Faculty of Sciences Semlalia, Marrakech, Morocco, 1993.

[8] A. Abdelbaki, S. Amjad, and Z. Zrikem, "Prediction of heat transfer from shallow basements to the soil by the two-dimensional transfer functions method", in: Proceedings of the 3rd Renewable Energy Congress, Reading, UK, 1994.

[9] S. Amjad, "Contribution à l'étude du comportement thermique des bâtiments semienterrés", DES thesis, Faculty of Sciences Semlalia, Marrakech, Morocco, 1997.

[10] S. Amjad, A. Abdelbaki, and Z. Zrikem, "Adaptation de la méthode des fonctions de transfert à une cavité enterrée", in: Proceedings of the 3rd Mechanical Congress, Tétouan, Morocco, pp. 497-502,1997.

[11] L. Boukhattem, A. Bendou, R. Mir, and M. Kourchi, "Simulation et optimisation des transferts de chaleur entre un bâtiment complètement enterré et le sol", Revue Internationale d'Héliotechnique, Energie Environnement, No 36, pp. 27-35, 2007.

[12] L. Boukhattem, A. Bendou, H. Hamdi, and D.R. Rousse, "Simulation bidimensionnelle du transfert d'énergie entre un bâtiment semienterré et le sol en régime variable", Revue internationale d'héliotechnique, $\mathrm{N}^{\circ} .44$, pp. 23-29, 2012. 